\title{
Inequalities in Spatial Accessibility of Childcare: The Role of Non-profit Providers
}

\author{
*WU Vienna University of Economics and Business \\ email: astrid.pennerstorfer@wu.ac.at \\ ** Johannes Kepler University Linz \\ email: dieter.pennerstorfer@jku.at
}

ASTRID PENNERSTORFER* (iD AND DIETER PENNERSTORFER** (i)

\begin{abstract}
Equal access to childcare services is a key concern of childcare policy. This article analyses social inequalities in the availability of such services. We explore how observed disparities are related to the socio-economic status of neighbourhoods and investigate how different provider types contribute to such differences. To do so, we use data on all childcare centres in the city of Vienna, Austria, on the spatial distribution of children aged under six and on three measures of neighbourhood status, over a period of eight years. We find that spatial accessibility is highest in neighbourhoods with the highest socioeconomic status, that such inequality has increased over time and that both effects can be attributed to the role of non-profits. The results indicate that the policy change undertaken in Vienna towards increased communitarisation - that is, a shift towards non-profit provision - has undermined the universal character of the city's childcare system.
\end{abstract}

Keywords: childcare; spatial accessibility; welfare mix; non-profit sector; Austria

\section{Introduction}

Equal distribution of welfare services is a central concern of public policy. However, disparities in the distribution of such services exist between different areas and different socio-economic groups (e.g., Kühn, 2015; Martinelli et al., 2017). The welfare mix, by which we mean the relative shares of public, non-profit, for-profit and informal provision, has been identified as one explanatory factor for these disparities (Leibetseder et al., 2017). Adjusting the welfare mix may help in catering to individual needs by leading to a variety of services tailored to different user groups. However, concerns have been voiced that recent trends in the 're-mix' of providers, which involve a shift away from direct public provision towards more market-oriented, non-profit or family-based provision of services that can be observed in many different welfare states, have actually increased inequalities in the distribution of services (Leibetseder et al., 2017, p. 149). 
This is a matter of particular concern for policy makers in the field of childcare. Indeed, the OECD (2001) has identified a universal approach to access as one of the key elements of successful childcare policy. As well as helping to increase female labour participation (e.g., Bauernschuster and Schlotter, 2015), the provision of good-quality, formal childcare infrastructure is regarded as important for children's cognitive and social development (e.g., Felfe and Lalive, 2018). Moreover, it contributes to the enhancement of families' lifesatisfaction (Yamauchi, 2010) and the reduction of poverty and inequality in society (e.g., Scheiwe and Willekens, 2009). Empirical findings further suggest that the benefits of childcare participation are especially pronounced for children from more disadvantaged backgrounds (e.g., Felfe and Lalive, 2018). It is therefore problematic that, in most Western countries, children from such backgrounds are less likely to attend formal childcare (e.g., Campbell et al., 2018; Van Lancker and Ghysels, 2016). There is an ongoing debate on the reasons for this inequality in childcare usage (e.g., Abrassart and Bonoli, 2015; Pavolini and Van Lancker, 2018; Van Lancker, 2018; Van Lancker and Ghysels, 2016), but differences in availability and affordability seem to be the most significant factors (Abrassart and Bonoli, 2015; Pavolini and Van Lancker, 2018).

The availability of childcare services incorporates various aspects. As well as sheer quantity, location is also important. Put differently, it is not enough simply to provide sufficient (affordable) childcare places for all socioeconomic groups; these places must also be located appropriately. Indeed, the spatial dimension can be regarded as a key factor, since childcare markets have often been described as geographically very small (e.g., Cleveland and Krashinsky, 2009; Hotz and Xiao, 2011; Pennerstorfer and Pennerstorfer, 2019), and because spatial proximity is usually mentioned by parents as one of their most important choice factors (e.g., Kim and Fram, 2009; Teszenyi and Hevey, 2015).

The availability and affordability of childcare are affected by various facets of welfare states (Van Lancker and Ghysels, 2016), of which one is the welfare mix. Investigating changes in the provider landscape is important as we can observe a transition from public to private provision in many different countries and welfare contexts (e.g., Lloyd and Penn, 2013, 2014). However, only limited attention has so far been paid to the question of whether institutional forms contribute to local disparities in the spatial availability of childcare services. In this article, we analyse such disparities for neighbourhoods of varying socio-economic composition in Vienna. We explore: (i) how these disparities are related to socio-economic status, and (ii) whether the provider type contributes to them. We use the terms availability and spatial accessibility synonymously throughout. Further, the terms childcare and day care (services) are used synonymously to refer to formal care services consisting of day care centres and crèches for children under the age of six. 
We contribute to the existing literature in a number of ways: First, existing research has not only established the crucial role of affordability in determining uptake of childcare services, but also that different provider types seem to react differently to potential consumers' financial constraints. Empirical findings suggest that wealthy neighbourhoods benefit relatively more from the entry of private providers, in particular for-profit firms (see e.g. Lee and Jang, 2017; Owens and Rennhoff, 2014; Small and Stark, 2005). So far, however, it has been difficult to evaluate whether such disparities arise only because affordability varies across neighbourhoods. Thanks to two 2009 policy changes in Vienna (see Section 3), we are able to fill this gap by investigating how spatial disparities are affected by a change in the welfare mix that is not driven by differences in affordability.

Our second contribution is that, rather than analysing differences in market entry (e.g., Owens and Rennhoff, 2014) or service quality (e.g., Cleveland and Krashinsky, 2009) across providers, we investigate children's spatial accessibility to childcare services. To do so, we apply a variant of the two-step floating catchment area method developed in the area of applied geography (see Radke and $\mathrm{Mu}, 2000$ ) and so far used - within the social sciences - mainly in health economics (e.g., Dai, 2010; Delamater, 2013; Luo and Qi, 2009; Luo and Wang, 2003). Third, given that socio-economic indicators vary much more between neighbourhoods within a city than between cities, focusing on a single city allows us to examine in close detail the relationship between local availability of childcare services and socio-economic differences.

In the next section of the paper, we discuss in greater detail the existing literature on disparities in the accessibility of childcare and the reasons for these. Section 3 then describes the specific Viennese situation as regards childcare provision. In Section 4, we describe the data that form the basis of our study and the method employed to analyse it. Section 5 then presents our results, while the paper concludes, in Section 6, with a discussion of these.

\section{Uneven access to childcare}

Differences in uptake of childcare by different socio-economic groups are a widespread phenomenon throughout European countries, although we find great diversity in their extent (Pavolini and Van Lancker, 2018; Van Lancker and Ghysels, 2016). While some European countries, such as Denmark or Iceland, exhibit (almost) no inequalities, in most others, children from of lower socio-economic status are significantly less likely to use childcare than those of higher status. Austria belongs to the latter group, as well as being among the countries with generally low utilisation rates of full-time care (Van Lancker and Ghysels, 2016, p. 321).

In general, the provision of childcare has been found to involve a complex interplay of demand and supply (Ellingsæter and Gulbrandsen, 2007), and the 
reasons for social inequality in utilisation are, as mentioned, manifold. Even after controlling for class differences in maternal employment rates, inequalities remain. Perhaps surprisingly, cultural norms regarding motherhood have been found to be relatively unimportant, while costs and availability are key explanatory variables (Abrassart and Bonoli, 2015; Pavolini and Van Lancker, 2018). Van Lancker and Ghysels (2016) additionally point to a number of welfare state characteristics associated with social inequality in utilisation, most importantly parental leave schemes, childcare quality and government involvement in the supply of childcare services.

This final point or, more broadly, the welfare mix in provision is also a focus of various studies concerned with disparities between provider types in the accessibility of childcare services (e.g., Baum and Oliver, 1996; Campbell et al., 2018; Cloney et al., 2016; Lee and Jang, 2017; Queralt and Witte, 1998; Small and Stark, 2005). Although its findings are not fully consistent, the affordability of childcare is seen as a central determinant in this line of research. The underlying assumption is that 'the distribution of institutional resources is driven by the market' (Small and Stark, 2005). In that vein, Noailly and Visser (2009) show how the introduction of market forces into a particular childcare market shifted provision to wealthy areas, while Owens and Rennhoff (2014) find that for-profits locate in areas with relatively more high-wage workers. Similarly, Lee and Jang (2017) and Small and Stark (2005) find for-profit providers to be a source of under-supply in disadvantaged neighbourhoods. Generally, both the public and the non-profit sectors are mentioned as a potential remedy for the inequitable distribution of facilities.

In assessing whether the non-profit sector is able to provide a more equitable distribution of services, it is useful to consider theories concerned to explain the sector's existence. According to Weisbrod (1975) for example, non-profits are likely to emerge predominantly in locations where accessibility to public or for-profit institutions is low. Such ideas also suggest that nonprofit organisations can reduce spatial inequalities. The theory of comparative advantage, which highlights differences between public and non-profit providers, posits that the non-profit sector has an advantage over public agents given the time and effort required for public agencies to respond to needs (Billis and Glennerster, 1998). Indeed, the argument for increased contracting-out of public services is based on the presumption that community-based organisations are more responsive to local needs than large, hierarchical government ones (Savas, 1987). Deliberations on non-profit failure (Salamon, 1987), on the other hand, mention the inability of non-profit organisations to 'generate resources on a scale that is both adequate enough and reliable enough to cope with the human service problems of an advanced industrial society' (Salamon, 1987, p. 111). The main reasons cited are a lack of resources and particularism, by which is meant the tendency for non-profit 
organisations to focus on servicing a narrow range of target groups (defined by religion, ethnicity, ideology or geography) while ignoring others.

Thus the relevant literature finds that the principal causes of inequality in childcare utilisation relate to affordability and availability. In measuring availability, however, spatial aspects have so far been treated rather crudely. Studies concerned with the spatial distribution of childcare facilities have mainly concentrated on comparing for-profit with public and non-profit providers, interpreting higher concentrations of childcare institutions in richer areas as a market reaction to higher levels of purchasing power and demand (e.g., Noailly and Visser, 2009). With regard to the question of whether nonprofit organisations are able to reduce inequalities in accessibility, the theoretical literature provides no clear guidance, as there are arguments for both a higher and a lower presence in neighbourhoods with lower socio-economic status.

\section{Childcare provision in Vienna}

We turn now to examine the provision of institutional childcare in Vienna, which involves three different types of nursery groups: groups for children under three only, groups for children aged three to five, and mixed-age groups for all children under six. Crucially, the framework within which provision is made experienced fundamental change in 2009. In that year, a legal requirement was introduced for children in their immediate pre-school year to attend day care for at least 16 hours a week. At the same time, the Vienna City Council introduced a new funding mode. Under this, full-time day care was made cost-free to all users - and widely promoted as such - although some small charges for ancillaries (e.g. materials or lunch) were maintained, and some non-profit providers continue to charge a small fee to cover extras such as extended opening hours. In return, the Council pays provider institutions a standard amount per child plus a lump sum.

Following these changes, Vienna's day-care market was to experience tremendous growth. Between 2007 and 2014, the number of day care institutions increased by $74 \%$, from 837 to 1,454 . In terms of coverage, $23.1 \%$ of all children under three and $83.1 \%$ of all children aged three to five attended a childcare institution in 2007. By 2014, however, the former proportion had almost doubled, to $40.2 \%$, and $92.6 \%$ of all children between three and five were in formal day care (Statistik Austria, 2015, p. 85).

The overall increase in supply was accompanied by a change in the mix of institutional providers. Here it should be noted that, even before 2009, day care was provided almost exclusively by public and non-profit institutions. In 2007 , for instance, only $5 \%$ of all day-care centres were run by private, for-profit organisations, whereas $38 \%$ were run by public providers and $56 \%$ by (private) non-profit institutions. The subsequent expansion of total supply was accompanied by a further shift towards the last group. As 


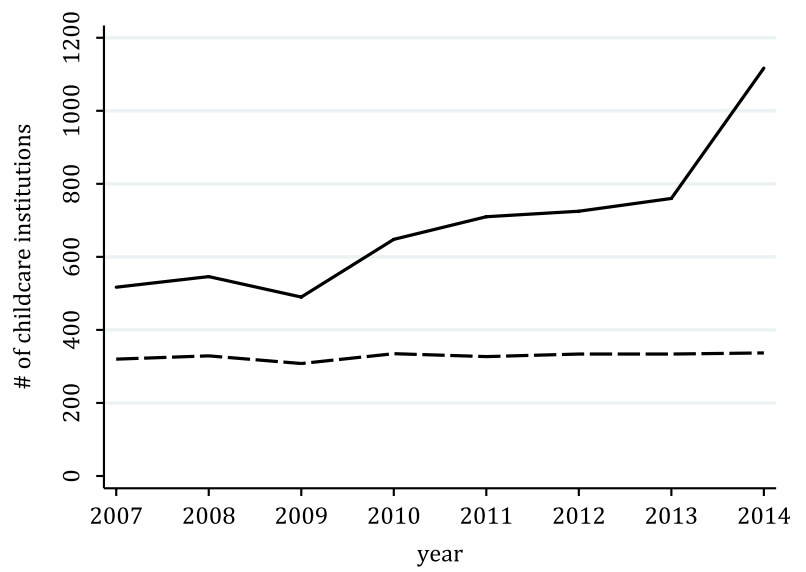

FIGURE 1. Day care institutions by provider type (2007-2014).

Notes: Dashed line $=$ public institutions in Vienna, solid line $=$ non-profit institutions

illustrated in Figure 1, growth took place almost exclusively in the non-profit sector, with public supply remaining more or less constant. Consequently, public agencies accounted for only $23 \%$ of all centres in 2014. Presumably, cost deliberations as well as organisational feasibility were important factors that help explain why the expansion was concentrated on non-profits rather than public services. Meanwhile, for-profit organizations had disappeared from the market entirely being ineligible for public funding (Stadt Wien, 2014), so that non-profit organisations accounted for the remaining $77 \%$. Thus, in terms of welfare mix, Vienna's childcare system experienced not marketisation, but an increase in the role of the non-profit sector, described by Leibetseder et al. (2017) as 'communitarisation'.

Given the universal character of the childcare service in Vienna (tax-funded and cost-free for all users), the theoretical considerations discussed in Section 2 would suggest that disparities in spatial accessibility to facilities between neighbourhoods of varying socio-economic status are unlikely. Moreover, we would expect any such disparities to have declined over time following the virtual elimination of childcare costs in 2009. One object of our study is to check whether these expectations are fulfilled. At the same time, the marked rise in the share of non-profit providers in Vienna from 2009 on provides us with an ideal opportunity to fill the gap in existing research identified at the end of Section 2 concerning the impact of non-profit provision on inequalities in spatial accessibility.

\section{Data and empirical strategy}

In order to assess disparities in spatial accessibility of childcare in Vienna, and the impact of increasing non-profit provision on these, we collected various types of 
data. As we will see, these data were available at four different levels of spatial disaggregation. These are: (i) $250 \mathrm{~m} \times 250 \mathrm{~m}$ grid cells independent of administrative boundaries, (ii) Vienna's 1,364 statistical enumeration districts (Zählsprengel - SEDs ${ }^{1}$ ), (iii) the city's 250 registration districts (Zählbezirke) and (iv) its 23 administrative districts (Bezirke). One type of data concerns the locations of children and childcare facilities. It is described in Subsection 4.1, which also sets out how these data were used to calculate measures of spatial accessibility. The second type, described in Subsection 4.2, relates to the socioeconomic status of areas within the city. Finally, in Subsection 4.3, we describe how the two data types were then combined to assess the relationship between accessibility and status.

\subsection{Spatial accessibility}

As noted by Cleveland and Krashinsky (2009), since transportation costs are high and account for a large fraction of total childcare costs, markets for childcare services are geographically very small. A spatial analysis consequently has to be performed on a regionally highly disaggregated level. To operationalize the concept of spatial accessibility, we were able to draw on two suitably disaggregated data sets, the first of which comprises data on all childcare facilities in Vienna during the period 2007-2014. These data, provided by the Vienna City Council (Magistratsabteilung 23), were collected in October of the year concerned. They include information on facilities' exact location ${ }^{2}$, their capacity (number of groups), the type of nursery groups (groups for children aged 0-2, for children aged 3-5, and for heterogeneous age groups) and the managing institution. Centres can thus be classified into public and non-profit providers.

The second data set is provided annually by the Austrian Statistical Office (Statistik Austria) for the same period (2007-2014). It comprises the entire population of Vienna, including the age and the place of residence of all individuals, at grid-cell level and thus provides extremely detailed information about the spatial distribution of the city's population. ${ }^{3}$ We focus on individuals of preschool age (i.e. aged under six), to whom we will refer henceforth as 'children'. ${ }^{4}$

To derive a measure of spatial accessibility, we apply a variant of the twostep floating catchment area method (2SFCA). This was first proposed by Radke and $\mathrm{Mu}$ (2000) and Luo and Wang (2003), and later refined by Luo and Qi (2009), Dai (2010) and Delamater (2013). The goal of the two-step floating catchment area method is to derive a measure of the spatial accessibility of overall provision for each child. The measure accounts: (i) for the distance between a child's place of residence and the location of all day care centres in the child's vicinity; (ii) for the size of these day care institutions; and (iii) for the number of children living in the catchment areas of the respective childcare facilities who potentially also need a slot in one of these day care centres. The process involved is illustrated in Figure 2. Map (a) shows the location of day care centres and the 

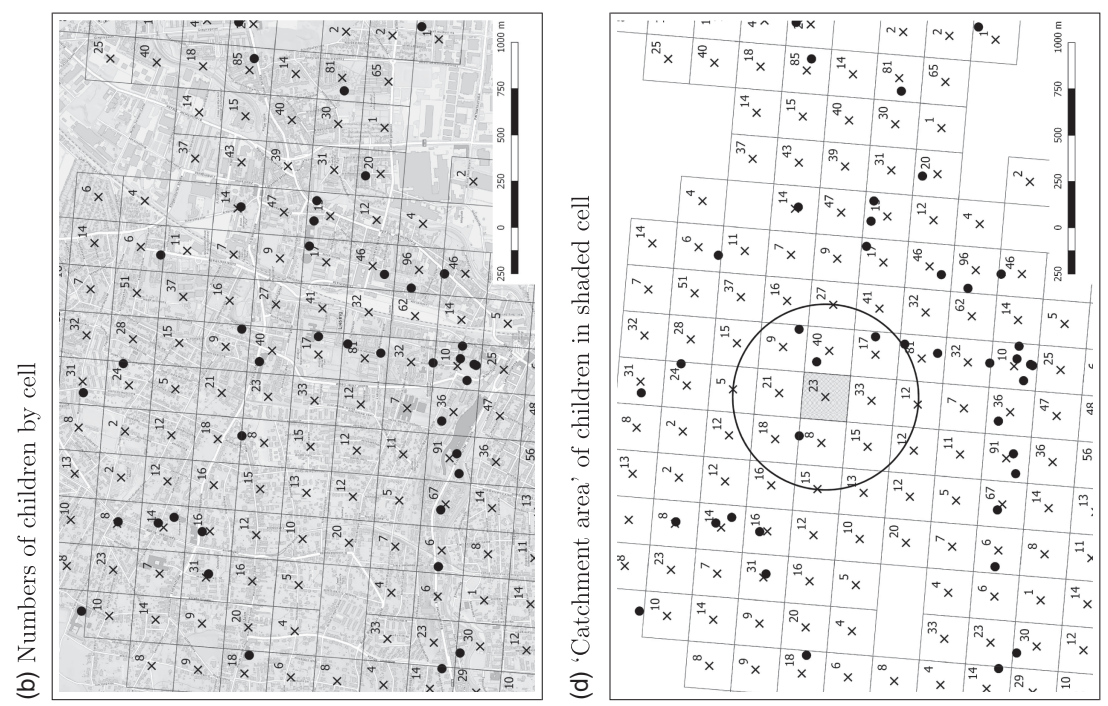


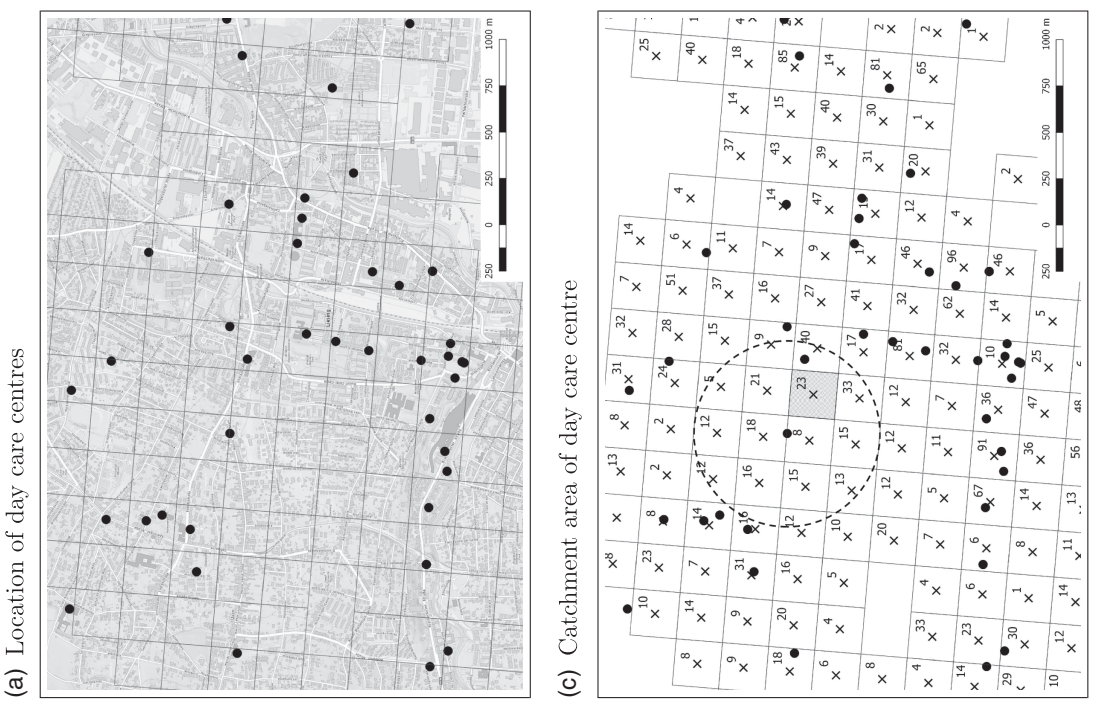

$\overline{\mathrm{Q}} \overline{\mathrm{g}}$

ล $x$

Ð

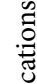

品

言苞

ปัँ

글

ปัँ

สิ

ㅎํ प्च

त्ञ

$\dot{\vec{g}}$

옴

$\times$

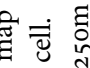

क 苛

के के

它氖苛

过要

ङ

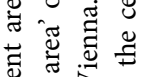

茟它

氜氙苛

on

윰 혼

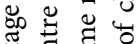

芯式苛

它芯 志

密各

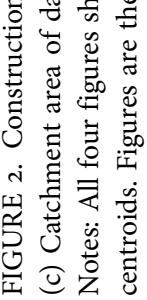


grid cells. Map (b) shows the centroid of each grid cell (marked ' $x$ ') and the number of children living in each cell.

In the first step, we aim at calculating the potential coverage of each day care centre by accounting for the number of children living in the catchment area of each childcare institution, indicated by a dashed circle in map (c) of Figure 2. We begin by calculating the weighted number of children in the catchment area of day care centre $d$. We use the distance ${ }^{5}$ decay function $f\left(\right.$ dist $\left._{d, c}\right)=$ dist $_{d, c}^{-2}$ between centre $d$ 's location and child $c$ 's place of residence to proxy demand decay ${ }^{6}$ and set the catchment area radius to $500 \mathrm{~m}$. In doing so, we follow Pennerstorfer and Pennerstorfer (2019), who provide evidence that catchment areas for day care services in metropolitan areas have radii no greater than $500 \mathrm{~m}$, and that demand falls off rapidly as the distance to the day care centre increases. The results provided in this article, however, are robust to larger catchment areas or alternative distance decay functions. Results based on a larger threshold distance $\left(\right.$ dist $\left._{\text {max }}=1 \mathrm{~km}\right)$ are reported in Tables 5 and 6 in Appendix C (available online), while Tables 7 and 8 in Appendix $\mathrm{C}$ summarize our estimates of accessibility measures based on a distance decay function $f\left(d i s t_{d, c}\right)=d i s t_{d, c}^{-1}$. In simple terms, this means that the closer children are located to the centre concerned, the higher the weight assigned to them. Children located outside the centre's catchment area are assigned zero weights. We then calculate a variable indicating the degree of potential coverage of centre $d, R_{d}$, as the inverse of the total weighted number of children in its catchment area (see equation (1)). This variable captures the idea that the accessibility of a particular childcare centre declines if the number of children in its catchment area increases and/or the locations of children within the catchment area move closer to the facility.

$$
R_{d}^{t}=\frac{1}{\sum_{c} f\left(\text { dist }_{d, c}\right)}, \text { with } f\left(\text { dist }_{d, c}\right)=0 \text { if } \text { dist }_{d, c}>\text { dist }_{\text {max }}
$$

In the second step of the 2 SFCA method, we focus on the spatial accessibility of overall provision for each child (see map (d) in Figure 2). In this second step, we account for the number of day care institutions within 500 metres of child c's place of residence, indicated by a solid circle in map (d), their capacity (number of groups) and their potential coverage. Again, institutions that are located closer to the child's place of residence are given higher weights than those located farther away. For the calculation of this second step, we first weight the potential coverage $R_{d}$ of facility $d$ by its capacity $k_{d}$ and by the distance decay function $f\left(\right.$ dist $\left._{c, d}\right)$. The weighted potential coverage of each provider is then summed for all centres located within 500 metres of child $c$ 's place of residence to give the total spatial accessibility of provision $A_{c}$ for child $c$ (see equation (2)). 


$$
A_{c}^{t}=\sum_{d} k_{d} R_{d}^{t} f\left(\text { dist }_{c, d}\right), \text { with } f\left(\text { dist }_{c, d}\right)=0 \text { if } \text { dist }_{c, d}>\text { dist }_{\max }
$$

$c$ child $c$

$d$ day care centre $d$

$t$ type of provider with

$t \in\{p u b, N P O\}$ for public or non-profit providers

$k_{d}$ capacity (\# of groups) of day care centre $d$

dist $_{c, d}=$ dist $_{d, c}$ Euclidean distance between location of child $c$ and day care centre $d$

dist $_{\text {max }}$ size of catchment area

$f\left(\right.$ dist $\left._{c, d}\right)$ distance decay function with $f\left(\right.$ dist $\left._{c, d}\right) \geq 0$ and $\frac{\partial f\left(\text { dist }_{c, d}\right)}{\partial \text { dist }_{c, d}} \leq 0$

$R_{d}^{t}$ indicator for the degree of potential coverage of day care centre $d$

$A_{c}^{t}$ accessibility level of child $c$

The accessibility measure $A_{c}$ is calculated every year for every child. It has a very intuitive interpretation since it increases:

- if the number of centres in the child's 'catchment area' rises;

- if these centres are located closer to the child's place of residence;

- if they increase in size (i.e., host a larger number of groups, indicated by capacity $k_{d}$ ); or

- if the weighted number of children within a centre's catchment area falls (indicated by an increased value of $R_{d}$ ).

Separate accessibility measures can be calculated for each provider type. Calculating the accessibility levels separately is essentially the same as taking the overall accessibility level interacted with the share of non-profit (or public) providers in the area. The former approach differs only in that because it weights the shares, with the weights used depending on the size and the potential coverage of each day care centre in the vicinity. Thus the spatial accessibility for child $c$ provided by facilities of type $t=p u b, A_{c}^{p u b}$, is the (weighted) sum of the potential coverage values of all public centres $R_{d}^{p u b}$, so that $A_{c}^{p u b}=\sum_{d} k_{d} R_{d}^{p u b} f\left(\right.$ dist $\left._{c, d}\right)$. Similarly, $A_{c}^{N P O}=\sum_{d} k_{d} R_{d}^{N P O} f\left(\right.$ dist $\left._{c, d}\right)$. The total accessibility $A_{c}$ is simply the sum over all centres, public or nonprofit, $A_{c}=A_{c}^{p u b}+A_{c}^{N P O}$. Hence, we can disentangle the spatial accessibility and evaluate how much each type of provider contributes to it for each child.

\subsection{Neighbourhood socio-economic status}

To capture the socio-economic status of a particular area of the city, we use three different measures based respectively on education level, income and house prices. Education level is assessed, on the basis of data for all residents aged over 14 in a particular grid cell provided by the Austrian Statistical 

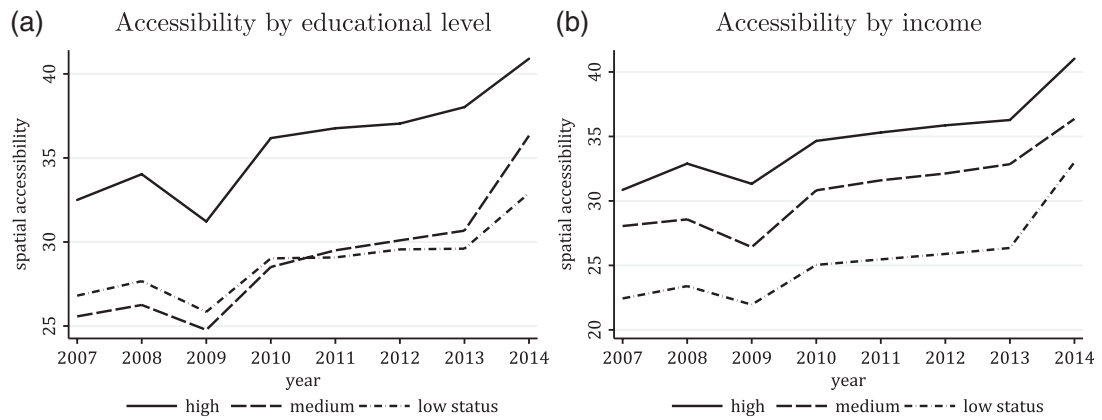

(c) Accessibility by house prices

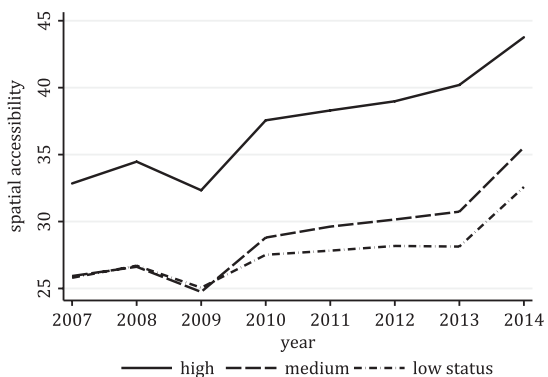

FIGURE 3. Spatial accessibility by neighbourhood socio-economic status (a) Accessibility by educational level (b) Accessibility by income (c) Accessibility by house prices.

Notes: All lines indicate the average spatial accessibility measure, $A_{c}$ (scaled by 1,00o), for all children in the year concerned.

Office for the year 2011, as the person's highest formal educational attainment. Specifically, we use the share of residents with a university degree or equivalent as our measure of each cell's status. Information on income is provided annually by the same source and is available for each year at the district level (see Bundesministerium für Digitalisierung und Wirtschaftsstandort, 2018a). Our income-based measure of status is the average individual net income of the district's residents. Finally, data on house prices, collected in 2015, are provided by the company 'DataScience' at the level of SEDs. As the related measure of status, we take the estimated purchase price of a standardized apartment located at the centroid of the SED. 7 In each case, we use the term 'neighbourhood' to refer to the smallest area for which data are available. 'Neighbourhoods' are thus smallest for our educational measure (grid cells) and largest for the income measure (districts). ${ }^{8}$

\subsection{Relating accessibility to neighbourhood status}

Preliminary indications of the relationship between the spatial accessibility of childcare and neighbourhood socio-economic status, for each of our three measures of status, are provided by Figures $3 \mathrm{a}$ to $3 \mathrm{c}$. For this purpose, the 
top $25 \%$ of neighbourhoods on a measure are classified as 'high-status', the middle $50 \%$ as 'medium-status' and the bottom $25 \%$ as 'low-status'. The figures show, first, that accessibility to day care steadily improved as a result of the massive expansion of day care provision after 2009, when the changes in legal requirements described in Section 3 came into force. Second, on all three measures of neighbourhood status, and throughout the whole period, spatial accessibility was consistently highest in high-status areas.

In order to obtain a more sophisticated picture of how spatial accessibility (for all children in all years) of each provider type relates to our measures of neighbourhood status, we estimate the following regressions by OLS.

$$
A_{c y}^{t}=\alpha+\beta S E S_{c y}+X_{c y} \theta+\mu_{y}+\varepsilon_{c y}
$$

Here, $A_{c y}^{t}$ indicates the accessibility measure for child $c$ in year $y$ from day care centres of type $t$. The variable $S E S_{c y}$ denotes the relevant measure of neighbourhood status and the corresponding parameter $\beta$ is the coefficient we wish to estimate. We control for additional neighbourhood characteristics $X_{c y}$ (with $\theta$ as the corresponding vector of parameters to be estimated), including the share of residents born in Austria, in (other) EU countries and outside the EU, the female employment rate, and information on public transport infrastructure, as well as for fixed time effects $\mu_{y}$ (to account for the overall increase in accessibility). $\alpha$ denotes the constant and $\varepsilon_{c y}$ the error term. Including variables reflecting residents' country of birth and female employment rates allows us to capture potential differences in preferences/ need with regard to the take-up of formal childcare. ${ }^{9}$ These additional variables are available at the grid cell level and were collected in 2007 by the Statistical Office. Finally, we include a dummy variable indicating the existence of an underground station in the respective grid cell as a further proxy for accessibility. ${ }^{10}$ An underground station close-by may increase demand relative to the number of children in the vicinity, as children from outside a day care centre's typical catchment area can access this facility more easily. Therefore, the presence of an underground station should be positively correlated with the measure of spatial accessibility. Summary statistics for all variables used in the empirical analyses are shown in Table 1. Note that the accessibility measures are calculated for each child every year between 2007 and 2014, giving a total of 814,672 observations. To confirm that the estimated relationship between neighbourhood status and accessibility is not driven by the parametric restriction, we also followed a semi-parametric approach (see Appendix A).

Finally, in order to investigate whether differences in the accessibility between neighbourhoods of differing socio-economic status changed over the 
TABLE 1. Summary statistics. Spatial accessibility and neighbourhood status

\begin{tabular}{|c|c|c|c|c|c|}
\hline Variable & \# obs. & Mean & S.D. & Min & Max \\
\hline \multicolumn{6}{|l|}{ Spatial accessibility } \\
\hline All groups $\left(A_{c} \times 1,000\right)$ & 814,672 & 30.608 & 29.038 & o & $3,480.00$ \\
\hline Public groups $\left(A_{c}^{\text {pub }} \times 1,000\right)$ & 814,672 & 12.568 & 17.850 & o & $1,818.18$ \\
\hline NPO groups $\left(A_{c}^{N P O} \times 1,000\right)$ & 814,672 & 18.040 & 22.681 & o & $3,160.00$ \\
\hline \multicolumn{6}{|l|}{ Measures of neighbourhood status } \\
\hline Education: university degree (in \%) & 814,115 & 16.442 & 10.487 & o & 100 \\
\hline Income: average income (in $1,000 € /$ year) & 814,672 & 20.559 & 2.802 & 15.80 & 34.33 \\
\hline House prices: price of flat (in $1,000 € / \mathrm{m}^{2}$ ) & 814,672 & 3.593 & 0.874 & 2.54 & 11.83 \\
\hline \multicolumn{6}{|l|}{ Control variables } \\
\hline Residents born in Austria (in \%) & 805,331 & 70.495 & 11.759 & 0 & 100 \\
\hline Residents born in other EU state (in \%) & 805,331 & 8.663 & 3.058 & o & 48.32 \\
\hline Residents born in ROW (in \%) & 805,331 & 20.842 & 10.695 & 0 & 99.35 \\
\hline Women in employment (in \%) & 805,329 & 40.167 & 7.656 & o & 78.95 \\
\hline Underground station (\#) & 814,672 & 0.034 & 0.182 & 0 & 1 \\
\hline
\end{tabular}

period under observation, we estimate further regressions which include an interaction term:

$$
A_{c y}^{t}=\alpha+\beta_{1} S E S_{c y}+\beta_{2} S E S_{c y} \times \text { time }_{y}+X_{c y} \theta+\mu_{y}+\varepsilon_{c y}
$$

with time $y$ going from zero (in the year 2007) to 7 (in the year 2014) and $\beta_{1}$ and $\beta_{2}$ as the parameters of interest.

\section{Results}

The results obtained by regressing spatial accessibility against each of our three status measures (equation 3) are presented in Table 2. Column 1 contains the coefficient values derived from regressing accessibility of all groups irrespective of provider, while columns 2 and 3 show the results for public and non-profit facilities, respectively. Focusing first on the results for all centres, we find that, for all three status measures, high-status neighbourhoods exhibit higher spatial accessibility to childcare. However, differentiating between provider types yields some interesting results. There is some evidence that public facilities offer higher accessibility for children in low-status neighbourhoods; negative coefficients are estimated for all three measures, but only that for educational attainment is statistically significant at any reasonable significance level. For non-profit centres, however, the picture is unambiguous, with significant positive coefficients estimated for all three measures. In other words, non-profit providers tend to locate in high-status neighbourhoods, while public ones have a less pronounced tendency to do so in poorer areas. All regressions include additional control variables, results on these control variables are reported in Table 10 in Appendix C, available online. 
TABLE 2. Coefficient values derived from regressing spatial accessibility of childcare against measures of neighbourhood status

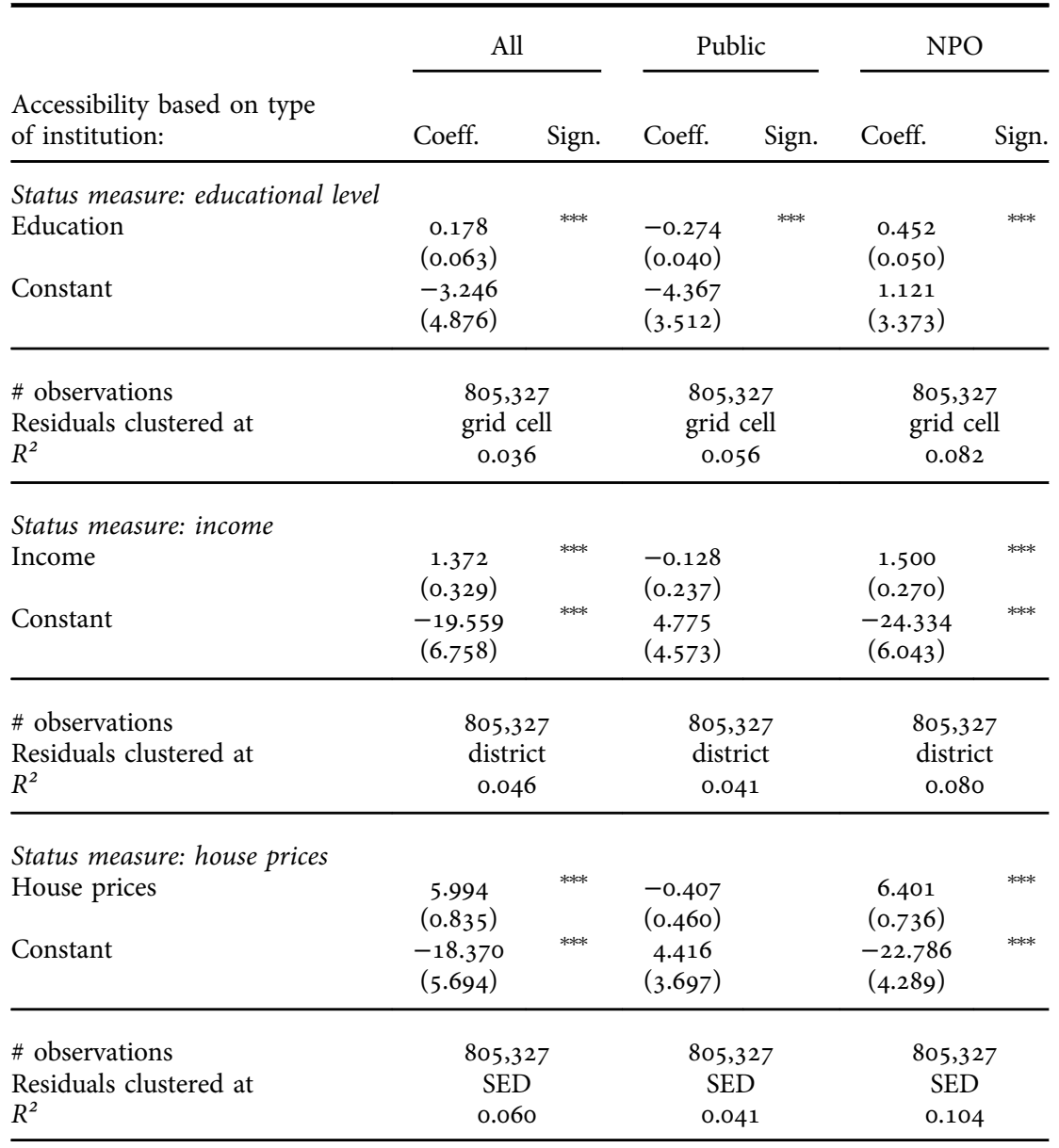

Notes: Accessibility measures are scaled by 1,00o. All regressions include fixed year effects and additional variables on neighbourhood characteristics (on female employment rates, share of residents born in Austria or in other EU countries, and on connectivity). Regression results on the control variables are reported in Table 10 in Appendix C, available online. Standard errors are reported in parentheses and are based on standard errors that are clustered at the geographical level at which the status measure concerned is available. ${ }^{* * *}$ significant at $1 \%$, ** significant at $5 \%,{ }^{*}$ significant at $10 \%$ level

In order to illustrate these effects more clearly, we calculate the expected value of spatial accessibility for the education status measure - both for all centres and separately for each provider type - based on the mean values of all control variables. We then calculate the ratio of the expected values for the 25 th and the $75^{\text {th }}$ percentile of neighbourhoods on the measure concerned, to which we refer as the 




FIGURE 4. Illustration of the coefficients on neighbourhood status.

Notes: Figure 4 illustrates ratios of the expected values of spatial accessibility (including confidence intervals) between neighbourhoods of high and low socio-economic status. Circles: all day care centres. Triangles: public day care centres. Diamonds: non-profit day care centres. The expected values of spatial accessibility are based on the point estimates on all explanatory variables. The confidence intervals of the ratios of the expected values of spatial accessibility are based on the upper and the lower bound of the $95 \%$-confidence interval of the parameter estimates of the education variable.

ratio between the top $25 \%$ and the bottom $25 \%$. When the accessibility of all centres is considered, this ratio takes the values 1.09. In other words, if two neighbourhoods, one being the top $25 \%$ and one the bottom $25 \%$ neighbourhood, contain the same number of children, we can expect to find $9 \%$ more groups in the first than in the second. Considering provider types separately results in the same pattern as was apparent from Table 2; accessibility to public centres is $26 \%$ lower in top- $25 \%$ neighbourhoods than in bottom- $25 \%$ ones, while accessibility to nonprofit providers is $44 \%$ higher. These results are represented graphically in the first column in Figure 4, where the circle indicates the result using all day care centres, the triangle indicates the results for public institutions and the diamond indicates the results for non-profit institutions. We repeat these calculations for the top and bottom $10 \%$, and for the top and bottom $1 \%$ of neighbourhoods. ${ }^{11}$ In the first case, the percentage advantage enjoyed by the higher-status neighbourhoods in access to facilities run by non-profits amounts to $98 \%$, while for the top and bottom $1 \%$ this value goes up to $166 \%$. These results strongly reinforce the finding that inequalities in accessibility are mainly driven by non-profit organisations. Using income or house prices as indicators of the socio-economic status of the neighbourhood gives very similar results, and the respective figures are thus suppressed for brevity. 
TABLE 3. Coefficient values derived from regressing spatial accessibility of childcare against measures of neighbourhood status including an interaction term

\begin{tabular}{|c|c|c|c|c|c|c|}
\hline \multirow{2}{*}{$\begin{array}{l}\text { Accessibility based on type } \\
\text { of institution: }\end{array}$} & \multicolumn{2}{|l|}{ All } & \multicolumn{2}{|c|}{ Public } & \multicolumn{2}{|c|}{ NPO } \\
\hline & Coeff. & Sign. & Coeff. & Sign. & Coeff. & Sign. \\
\hline $\begin{array}{l}\text { Status measure: educational level } \\
\text { Education }\end{array}$ & $\begin{array}{c}0.129 \\
(0.060)\end{array}$ & $* *$ & $\begin{array}{l}-0.273 \\
(0.039)\end{array}$ & **** & $\begin{array}{c}0.402 \\
(0.047)\end{array}$ & $* * *$ \\
\hline Education $\times$ time & $\begin{array}{c}0.014 \\
(0.005)\end{array}$ & ** & $\begin{array}{l}0.000 \\
(0.002)\end{array}$ & & $\begin{array}{c}0.014 \\
(0.005)\end{array}$ & $* * *$ \\
\hline Constant & $\begin{array}{l}-2.435 \\
(4.892)\end{array}$ & & $\begin{array}{l}-4.389 \\
(3.530)\end{array}$ & & $\begin{array}{l}1.955 \\
(3.374)\end{array}$ & \\
\hline $\begin{array}{l}\text { \# observations } \\
\text { Residuals clustered at } \\
R^{2}\end{array}$ & \multicolumn{2}{|c|}{$\begin{array}{l}805,327 \\
\text { grid cell } \\
0.036\end{array}$} & \multicolumn{2}{|c|}{$\begin{array}{c}805,327 \\
\text { grid cell } \\
0.056\end{array}$} & \multicolumn{2}{|c|}{$\begin{array}{c}805,327 \\
\text { grid cell } \\
0.082\end{array}$} \\
\hline $\begin{array}{l}\text { Status measure: income } \\
\text { Income }\end{array}$ & $\begin{array}{c}1.353 \\
(0.267)\end{array}$ & *** & $\begin{array}{l}-0.175 \\
(0.250)\end{array}$ & & $\begin{array}{c}1.528 \\
(0.253)\end{array}$ & $* * *$ \\
\hline Income $\times$ time & $\begin{array}{l}0.005 \\
(0.034)\end{array}$ & & $\begin{array}{l}0.013 \\
(0.012)\end{array}$ & & $\begin{array}{l}-0.008 \\
(0.037)\end{array}$ & \\
\hline Constant & $\begin{array}{c}-19.171 \\
(6.438)\end{array}$ & $* * *$ & $\begin{array}{c}5.706 \\
(4.326)\end{array}$ & & $\begin{array}{c}-24.877 \\
(6.030)\end{array}$ & $* * *$ \\
\hline $\begin{array}{l}\text { \# observations } \\
\text { Residuals clustered at } \\
R^{2}\end{array}$ & \multicolumn{2}{|c|}{$\begin{array}{c}805,327 \\
\text { district } \\
0.046\end{array}$} & \multicolumn{2}{|c|}{$\begin{array}{c}805,327 \\
\text { district } \\
0.041\end{array}$} & \multicolumn{2}{|c|}{$\begin{array}{c}805,327 \\
\text { district } \\
0.080\end{array}$} \\
\hline \multicolumn{7}{|l|}{ Status measure: house prices } \\
\hline House prices & $\begin{array}{c}4.978 \\
(0.774)\end{array}$ & *** & $\begin{array}{l}-0.411 \\
(0.439)\end{array}$ & & $\begin{array}{c}5.389 \\
(0.704)\end{array}$ & *** \\
\hline House prices $\times$ time & $\begin{array}{l}0.286 \\
(0.076)\end{array}$ & $* * *$ & $\begin{array}{l}0.001 \\
(0.026)\end{array}$ & & $\begin{array}{l}0.285 \\
(0.073)\end{array}$ & $* * *$ \\
\hline Constant & $\begin{array}{c}-14.706 \\
(5.646)\end{array}$ & *** & $\begin{array}{l}4.430 \\
(3.756)\end{array}$ & & $\begin{array}{l}-19.136 \\
(4.178)\end{array}$ & $* * *$ \\
\hline \multirow{3}{*}{$\begin{array}{l}\text { \# observations } \\
\text { Residuals clustered at } \\
R^{2}\end{array}$} & \multicolumn{2}{|c|}{805,327} & \multicolumn{2}{|c|}{805,327} & \multicolumn{2}{|c|}{805,327} \\
\hline & \multirow{2}{*}{\multicolumn{2}{|c|}{ SED }} & \multicolumn{2}{|c|}{ SED } & \multirow{2}{*}{\multicolumn{2}{|c|}{$\begin{array}{l}\text { SED } \\
0.105\end{array}$}} \\
\hline & & & 0.0 & & & \\
\hline
\end{tabular}

Notes: Accessibility measures are scaled by 1,000 . All regressions include fixed year effects and additional variables on neighbourhood characteristics (on female employment rates, share of residents born in Austria or in other EU countries, and on connectivity). Regression results on the control variables are reported in Table 11 in Appendix C, available online. 'Time' indicates the year of observation, running from o (2007) to 7 (2014). Standard errors are reported in parentheses and are based on standard errors that are clustered at spatial level for which data for the relevant status measure are available. ${ }^{* * *}$ significant at $1 \%$, ** significant at $5 \%$, * significant at $10 \%$ level. 
Turning now to the question of whether inequalities between neighbourhoods changed over the sample period, we consider the results of the regressions described by equation (4). These results are summarised in Table 3. When spatial accessibility to all centres, irrespective of provider, is considered, and for the status measures house prices and educational level, the coefficient of the term introduced to account for time-related effects $\left(\beta_{2}\right)$ is positive and statistically significant. This indicates that inequalities in accessibility between neighbourhoods increased over time; in other words, areas with higher socio-economic status benefited disproportionately from the expansion of childcare.

However, when public facilities alone are considered, $\beta_{2}$ does not differ from zero even at the $10 \%$ significance level for any measure: This suggest that public providers did not change their strategic orientation as regards the location of facilities in neighbourhoods of varying status. Their continuing weak focus on lower status areas, combined with the lack of growth in total public provision, increased the gap between growing demand and public supply of childcare services there. This widening gap could have been filled by non-profits if they had expanded their services predominantly in lower status areas. However, the results in Table 3 suggest they did not. Not only do non-profit facilities contribute more strongly to spatial accessibility the higher a neighbourhood's status, for two out of three measures of that status the resultant disparity increased over time. It would therefore seem that growth in the number and the market share of non-profit facilities contributed significantly to increasing inequality in the overall spatial accessibility to childcare services over the study period.

\section{Discussion and conclusions}

In the analysis of socio-economic inequalities in utilisation of childcare, previous studies have found availability and affordability to be key variables. This study has focused on the spatial dimension of availability. Unsurprisingly, over a period of massive expansion of childcare in Vienna, it found an overall increase in spatial accessibility. However, this improvement varied between neighbourhoods. Throughout the period, spatial accessibility to childcare was better in neighbourhoods with higher socio-economic status. Additionally, these areas benefited disproportionately from the overall improvement in accessibility, which further increased inequalities. A disaggregation by provider type revealed that this effect was driven by the non-profit sector. Conversely, accessibility to public institutions actually tends to be higher in more deprived areas (although this result is not robust across all measures of neighbourhood status used in this article). It is important to stress that the relation found between accessibility (by provider type) and neighbourhood status is descriptive rather than causal, since we do not explicitly model the interdependence between the location choices of non-profit and public providers. Furthermore, the socio-economic status of a neighbourhood could be endogenous; households might move to 
areas where the accessibility to childcare is superior, and more affluent parents could do this more often (see the discussion on this issue in Pennerstorfer and Pennerstorfer, 2019).

How can the higher prevalence of non-profit providers in areas with higher socio-economic status be explained? At first glance, it seems rather surprising that such facilities should be distributed unevenly, given that they receive the same public funding irrespective of their location. We can only hypothesize about the reasons. The first possible cause is the existence of differences in parental preferences, themselves perhaps resulting from differences in the opportunity cost of time and/or unequal labour participation rates across parents of different socio-economic groups. In other words, better educated and more affluent parents may have a greater need for childcare services. Given that public providers serve all neighbourhoods (roughly) equally, nonprofits may simply respond to differences in demand by providing childcare services predominantly in wealthier areas.

Nonetheless, this explanation does not appear plausible in our context. On the one hand, there is no intuitive economic explanation for why differences in preferences should have increased over time, bearing in mind that the costs of formal childcare for parents decreased sharply after 2009. On the other hand, the age at which children start attending formal day care centres varies. However, since 2009 all children must attend a facility in their pre-school year (see Section 3), and in fact nearly all children do so from age three. It is thus reasonable to expect that preferences differ more among parents of children younger than three. Consequently, in an alternative specification, we effectively divided our analysis into two parts. In one, we considered the accessibility for toddlers (under threes) of nursery groups designed for this age group (see Section 3), in the other, the accessibility for 3-5-year olds of nursery groups catering to them. We then performed the same analyses separately for these two distinct cases. The results are reported in Table 4 in Appendix B. These show similar patterns of inequality for both age groups. While heterogeneous preferences between socio-economic groups may result in unequal access for toddlers, they can hardly explain the inequality for older children. This finding thus further undermines the hypothesis that different parental preferences across socio-economic groups can help explain the observed unequal distribution of non-profit facilities.

An alternative potential explanation highlights differences in parental resources. Admittedly, childcare is promoted as free of charge for parents, and the additional monetary fees charged by some organisations are relatively low. However, they could still prevent parental take-up/demand in poorer areas. Moreover, some charges involve non-monetary resources, such as time. As volunteering rates differ across socio-economic classes (e.g., Bekkers, 2007), and since the expectation that parents will volunteer their time may be higher 
in non-profit institutions, such charges may further deter demand from parents of lower socio-economic status. It is also worth noting that entrepreneurial consumers could be an important factor here, since many small non-profit providers of childcare are founded by parents. An uneven distribution of such entrepreneurial skills and activity between socio-economic groups is very plausible. Finally, differing parental preferences for alternative pedagogical concepts, on which many non-profits focus, could be a further significant factor.

While the results presented provide evidence of non-profit failure, there is certainly room for the analysis to be improved in future studies. For example, we disregarded such important aspects as opening hours and other quality aspects. Furthermore, the reasons for the increased presence of non-profit providers in areas with higher socio-economic status constitute an important unexplored area. Given the great heterogeneity of the non-profit sector, differences in spatial accessibility within it could usefully be explored.

With regard to the welfare mix, our results indicate that the policy change in Vienna towards greater communitarisation (that is, a shift towards non-profit provision) has undermined the universal character of the childcare system. As regards the question of whether this result can be generalized to other contexts, the study - among other things - points out that it is important to differentiate between public and non-profit providers. Previous research has tended to see both the public and the non-profit sectors as potential remedies for inequalities in childcare availability caused largely by for-profit providers (see Section 2). In contrast, our study finds that, even in a context where affordability should be largely irrelevant, there are still inequalities in availability for different socioeconomic groups. Also in contrast to our findings are those of Campbell et al. (2018), among others, who find non-profit institutions to be relatively successful in reaching children from lower-income backgrounds. An important explanation given by these authors is the greater willingness of non-profit providers in the UK to offer places in the middle of the academic year. This suggests that it is important to account for regulatory differences between provider types and legislations when accounting for differences in accessibility between institutional sectors.

While differences between provider types should thus be studied in the specific context, this article provides a framework for future research. The methodological approach can be used to assess spatial inequalities in a cross-section or to evaluate the effects of policy changes in a longitudinal setting. Data for such analyses are usually easily accessible since locations of service providers are often publicly available (and can be obtained, e.g., via web scraping). The distribution of the population at a fine spatial resolution is also becoming more widespread. Consequently, this approach can be applied also to other service ranges and other cities or regions where the spatial location of a provider is of importance. 
For the city government, in order to secure an equal distribution of providers in the city, adequate funding of the institutions is of importance if universal access is a policy goal. Otherwise, the re-mix of childcare providers towards the non-profit provision can be problematic because it creates spatial inequalities in the accessibility between socio-economic groups.

\section{Acknowledgements}

The authors would like to thank Karin Heitzmann, conference participants of the 2018 International Conference of the International Society for Third Sector Research and the 2019 ESPAnet Austria Research Conference, as well as seminar participants at the Johannes Kepler University Linz and the Vienna University of Economics and Business for helpful comments on earlier versions of this manuscript. The authors also thank the Magistratsabteilung 10 (City of Vienna) for collecting and the Magistratsabteilung 23 (City of Vienna) for providing data on child care institutions, Julia Groiß for providing assistance to prepare the data set, and Christopher Ross for proofreading the manuscript. This research did not receive any specific grant from funding agencies in the public, commercial, or not-for-profit sectors.

\section{Notes}

1 SEDs differ significantly from one another in both size and socio-demographic composition. They are not 'merely artificial "statistical spaces" but are closely related either to historicaltopographical quarters or to newly built-up areas at the urban fringe' (Eurofound, 2009, p. 9).

2 Geographical information was provided at the level of registration districts, each of which contains only a few facilities (4.4 on average). In order to attach exact postal addresses to facilities, the childcare institutions were linked to data reported in 'Vienna's childcare guides' published by the Wiener Familienbund in 2005 and 2011, as well as to open government data published by the City Council. Since the type of institution running each facility, as well as other characteristics such as opening hours, are reported in both data sets, linking the two was straightforward, if time-consuming. The postal addresses were geo-coded and could thus be linked with spatial data on demand indicators. We are grateful to Julia Groiß for assistance in linking the two data sets.

3 These population data were collected on 1 January of the year concerned (exception: 2007 data were collected on 31 October 2006). They were thus always collected before information on day care facilities was surveyed.

4 While the number of residents is given for all cells, data on the age structure is provided only for cells with more than 30 residents (until 2011) or 3 residents (since 2011). As a result, we were unable to consider in our analysis a small share (about $0.3 \%$ ) of the total population.

5 We use straight-line (Euclidean) rather than travel distances for computational reasons. Calculations based on a sub-sample (using data of one district with a population of about 100,000 ) suggest a correlation between straight-line and driving distance of 0.86 .

6 We assume that both children and day care centres are located at the centroid of the relevant grid cell. The distance dist $_{d, c}$ between day care centres and children located in the same grid cell is set to $125 \mathrm{~m}$ to approximate travel distance within one grid cell.

7 We are grateful to Wolfgang Brunauer and Ronald Weberndorfer of DataScience for sharing these data with us. A detailed description of the methodology used to estimate house prices is provided in Brunauer et al. (2017). 
8 In our analysis, we use three indicators of neighbourhood socio-economic status independently. In order to carry out a sensitivity analysis, we used a composite index variable based on all three measures. Results of this analysis are reported in Table 9 in Appendix C, available online.

9 Note that our measures of potential coverage $R_{d}$ and spatial accessibility $A_{c}$ depend on the observed number of children in the vicinity. If female employment rates are low, the need for formal childcare may be low as well, and the number of children may thus overestimate actual demand. As a result, the accessibility measure $A_{c}$ will underestimate the true spatial accessibility to formal childcare. A positive coefficient for female employment rate should reflect that the correlation between the number of children and the need for childcare is systematically (and positively) related to female employment rates.

10 Data on the location of underground stations is available annually (Bundesministerium für Digitalisierung und Wirtschaftsstandort, 2018b).

11 Again, we use the terms 'top 10\%' ('top 1\%') and 'bottom 10\%' ('bottom 1\%') to refer to the 1oth (1st) and the 9oth (99th) percentile, respectively.

\section{Supplementary material}

To view supplementary material for this article, please visit https://doi.org/10. $1017 /$ Soo47279419000990

\section{References}

Abrassart, A. and Bonoli, G. (2015). Availability, cost or culture? Obstacles to childcare services for low-income families. Journal of Social Policy, 44(4):787-806.

Bauernschuster, S. and Schlotter, M. (2015). Public child care and mothers' labor supplyevidence from two quasi-experiments. Journal of Public Economics, 123:1-16.

Baum, J. A. C. and Oliver, C. (1996). Toward an institutional ecology of organizational founding. Academy of Management Journal, 39(5):1378-1427.

Bekkers, R. (2007). Intergenerational transmission of volunteering. Acta Sociologica, 50(2):99-114.

Billis, D. and Glennerster, H. (1998). Human services and the voluntary sector: Towards a theory of comparative advantage. Journal of Social Policy, 27(1):79-98.

Brunauer, W., Feilmayr, W., and Wagner, K. (2017). Der österreichische Wohnimmobilienpreisindex: Methodische Verfeinerung 2017 (The Austrian residential real estate price index: methodological refinement 2017). Statistiken: Daten \& Analysen, 18(Q4):64-71.

Bundesministerium für Digitalisierung und Wirtschaftsstandort (2018a). Dependent unit income in 23 municipal districts in Vienna by sex since 2002. Technical report https://www.data.gv.at/katalog/dataset/8f405794-d95b-4d12-922a-850045bb6870;

Accessed: November 29, 2018.

Bundesminsterium für Digitalisierung und Wirtschaftsstandort (2018b). U-Bahnnetz Bestand Wien. (Underground system in Vienna). Technical report. https://www.data.gv.at/ katalog/dataset/stadt-wien_ubahnnetzbestandwien: Accessed: July 30, 2019.

Campbell, T., Gambaro, L., and Stewart, K. (2018). 'Universal' early education: Who benefits? Patterns in take-up of the entitlement to free early education among three-year-olds in England. British Educational Research Journal, 44(3):515-538.

Cleveland, G. and Krashinsky, M. (2009). The nonprofit advantage: Producing quality in thick and thin child care markets. Journal of Policy Analysis and Management, $28(3): 440-462$. 
Cloney, D., Cleveland, G., Hattie, J., and Tayler, C. (2016). Variations in the availability and quality of early childhood education and care by socioeconomic status of neighborhoods. Early Education and Development, 27(3):384-401.

Dai, D. (2010). Black residential segregation, disparities in spatial access to health care facilities, and late-stage breast cancer diagnosis in metropolitan Detroit. Health \& Place, 16(5):1038-1052.

Delamater, P. L. (2013). Spatial accessibility in suboptimally configured health care systems: A modified two-step floating catchment area (M2SFCA) metric. Health \& Place, 24:30-43.

Ellingsæter, A. L. and Gulbrandsen, L. (2007). Closing the childcare gap: The interaction of childcare provision and mothers' agency in Norway. Journal of Social Policy, 36(4):649-669.

Eurofound (2009). Housing and segregation of migrants. Case Study: Vienna, Austria. European Foundation for the Improvement of Living and Working Conditions, Dublin, Ireland.

Felfe, C. and Lalive, R. (2018). Does early child care affect children's development? Journal of Public Economics, 159:33-53.

Hotz, V. J. and Xiao, M. (2011). The impact of regulations on the supply and quality of care in child care markets. American Economic Review, 101(5):1775-1805.

Kühn, M. (2015). Peripheralization: Theoretical concepts explaining socio-spatial inequalities. European Planning Studies, 23(2):367-378.

Kim, J. and Fram, M. S. (2009). Profiles of choice: Parents' patterns of priority in child care decision-making. Early Childhood Research Quarterly, 24(1):77-91.

Lee, J. and Jang, Y. J. (2017). Equal access to early childhood education in South Korea using the geographic information system. International Journal of Early Years Education, 25(2):171-189.

Leibetseder, B., Anttonen, A., Øverbye, E., Pace, C., and Vabo, S. I. (2017). The horizontal 're-mix' in social care: Trends and implications for service provision, pages 134-154. Edward Elgar Publishing, Cheltenham, UK Northampton, MA, USA.

Lloyd, E. and Penn, H. (2013). Childcare markets. Can they deliver an equitable service. Policy Press, Bristol.

Lloyd, E. and Penn, H. (2014). Childcare markets in an age of austerity. European Early Childhood Education Research Journal, 22(3):386-396.

Luo, W. and Qi, Y. (2009). An enhanced two-step floating catchment area (E2SFCA) method for measuring spatial accessibility to primary care physicians. Health \& Place, 15(4):1100-1107.

Luo, W. and Wang, F. (2003). Measures of spatial accessibility to health care in a GIS environment: Synthesis and a case study in the Chicago region. Environment and Planning B: Planning and Design, 30(6):865-884.

Martinelli, F., Anttonen, A., and Mätzke, M. (2017). Social services disrupted: Changes, challenges and policy implications for Europe in times of austerity. Edward Elgar Publishing, Cheltenham, UK Northampton, MA, USA.

Noailly, J. and Visser, S. (2009). The impact of market forces on child care provision: Insights from the 2005 child care act in the Netherlands. Journal of Social Policy, 38(03):477-498.

OECD (2001). Starting Strong. OECD Publishing, Paris.

Owens, M. F. and Rennhoff, A. D. (2014). Provision and price of child care services: For-profits and nonprofits. Journal of Urban Economics, 84(Supplement C):40-51.

Pavolini, E. and Van Lancker, W. (2018). The Matthew effect in childcare use: a matter of policies or preferences? Journal of European Public Policy, 25(6):878-893.

Pennerstorfer, A. and Pennerstorfer, D. (2019). How small are small markets? Local market size for child care services. Regional Science and Urban Economics, 77 (7), 340-355.

Queralt, M. and Witte, A. D. (1998). Influences on neighborhood supply of child care in Massachusetts. Social Service Review, 72(1):17-46.

Radke, J. and Mu, L. (2000). Spatial decompositions, modeling and mapping service regions to predict access to social programs. Geographic Information Sciences, 6(2):105-112. 
Salamon, L. M. (1987). Of market failure, voluntary failure, and third-party government: Toward a theory of government-nonprofit relations in the modern welfare state. Journal of Voluntary Action Research, 16(1-2):29-49.

Savas, E. (1987). Privatization: The key to better government. Chatham House, Chatham, NJ. Scheiwe, K. and Willekens, H. (2009). Childcare and preschool development in Europe. Palgrave Macmillan, London.

Small, M. and Stark, L. (2005). Are poor neighborhoods resource deprived? A case study of childcare centers in New York. Social Science Quarterly, 86(5):1013-1036.

Stadt Wien (2014). Informationsleitfaden Anstoßfinanzierung. (Guidelines initial funding). Report, Wiener Kindergärten (Magistratsabteilung 10), https://www.wien.gv.at/bildung/ kindergarten/ahs-info/pdf/informationsleitfaden-anstossfinanzierung-privat.pdf; Accessed: January 15, 2019.

Statistik Austria (2015). Kindertagesheimstatistik. (Statistic on child care facilities). Verlag Österreich, Wien

Teszenyi, E. and Hevey, D. (2015). Age group, location or pedagogue: Factors affecting parental choice of kindergartens in Hungary. Early Child Development and Care, 185(11-12, SI):1961-1977.

Van Lancker, W. (2018). Reducing inequality in childcare service use across European countries: What (if any) is the role of social spending? Social Policy \& Administration, 52(1):271-292.

Van Lancker, W. and Ghysels, J. (2016). Explaining patterns of inequality in child- care service use across 31 developed economies: A welfare state perspective. International Journal of Comparative Sociology, 57(5):310-337.

Weisbrod, B. A. (1975). Toward a theory of the voluntary nonprofit sector in a three-sector economy. Russell Sage Foundation, New York. Reprinted in S. Rose- Ackerman (ed.) (1986) The Economics of Nonprofit Organizations: Studies in Structure and Policy, Oxford University Press, New York.

Yamauchi, C. (2010). The availability of child care centers, perceived search costs and parental life satisfaction. Review of Economics of the Household, 8(2):231-253.

Yatchew, A. (1998) Nonparametric regression techniques in economics. Journal of Economic Literature, 36: 669-721.

\section{Appendix A. Results of the semi-parametric approach}

To allow the relationship between the measure of spatial accessibility $A_{c y}$ and neighbourhood status to be non-linear, we alternatively estimate the relation between accessibility and neighbourhood characteristics semi-parametrically. While keeping a linear specification for the vector of controls, we impose no parametric restrictions on the relationship between socio-economic status and accessibility, and thus estimate the following equation semi-parametrically:

$$
A_{c y}^{t}=\alpha+f\left(S_{C S}\right)+X_{c y} \theta+\mu_{y}+\varepsilon_{c y}
$$

To obtain an estimate $\hat{f}(\cdot)$, we apply the difference estimator outlined in Yatchew (1998). We first sort the data according to the variable SES (i.e. the relevant measure of neighbourhood status) and estimate the first derivative of equation (5):

$$
\Delta A_{c y}^{t}=\Delta f\left(S E S_{c y}\right)+\Delta X_{c y} \theta+\Delta \mu_{y}+\Delta \varepsilon_{c y}
$$

As $S E S$ is a smooth variable, $\triangle f(S E S)$ cancels out in equation (6). We are thus able to obtain a consistent estimate of $\theta$ and the time fixed effects without explicitly modelling $f(S E S)$. Finally, we regress $A^{t}-X \hat{\theta}-\hat{\mu}$ against SES non-parametrically to obtain our estimate $f($.$) .$

Figure 5 shows the results obtained for the non-parametric component of equation (5) with a kernel-weighted local polynomial regression. It illustrates how accessibility to childcare varies 

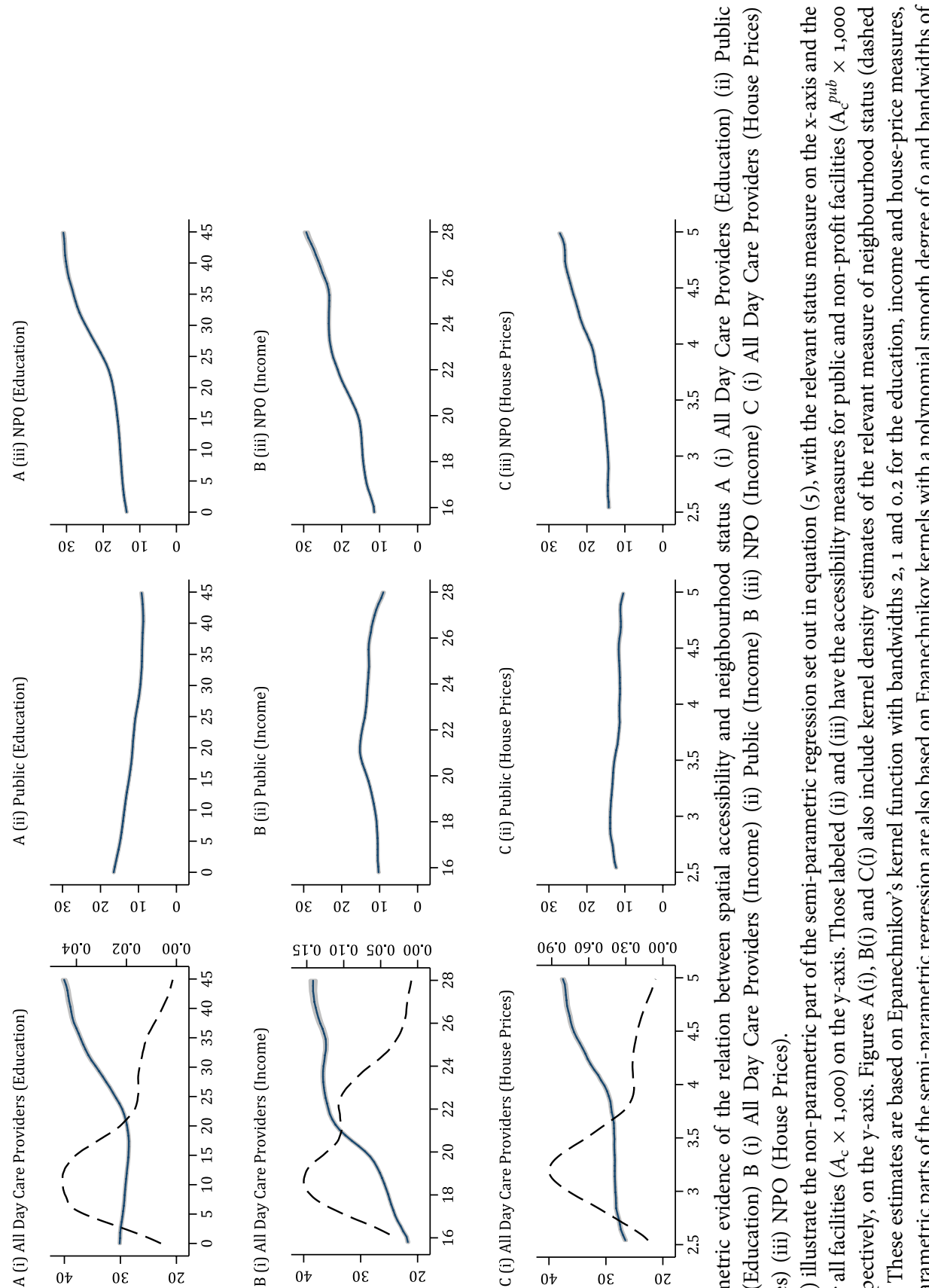

进息 ङ 节范

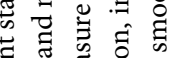
ฐ 己

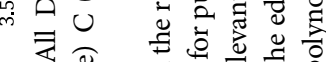



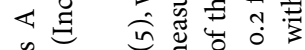
ก

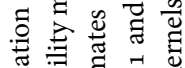

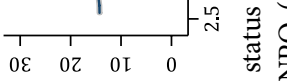

跑言苛 ○ :

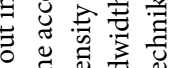
$\pm \mp$ च

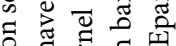



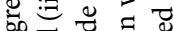

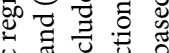

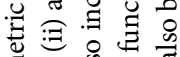
త్ర ปี

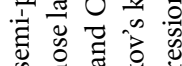
क ํํำ

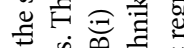
ญ 莒它 光文艺 䓃

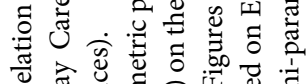
๑

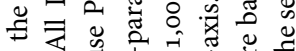
फ ช $ص$ I

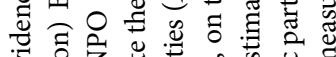
己

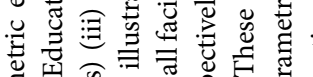

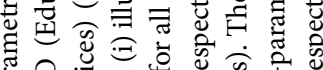

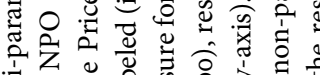
声

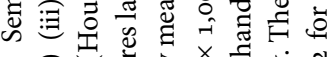

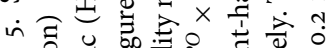

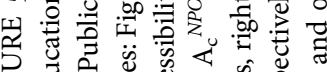

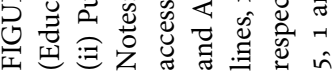


between neighbourhoods with lower and higher socio-economic status. Sections A to C each relate to one of our status measures. In all models labelled (i), the spatial accessibility measure is based on all groups $\left(A_{c y}\right)$, while specifications based on public groups only $\left(A_{c y}^{p u b}\right)$ and non-profit groups only $\left(A_{c y}^{N P O}\right)$ are labelled (ii) and (iii), respectively. Again, the results make evident that spatial accessibility to day care is lower in lower-status neighbourhoods, and that the non-profit sector can be made accountable for this finding. Results for the public sector are less stable. Using education as status measure, we find higher accessibility to public institutions in lower-status areas, but the pattern is more ambiguous when status is measured by income or housing prices.

\section{Appendix B. Accessibility for different age groups}

In this sensitivity analysis we investigate whether the pattern found in the main part of the article for all children, with non-profits being more active in higher-status neighbourhoods, is replicated both for children under three (toddlers) and for children aged three to five. To calculate the spatial accessibility measure $A_{c y}$ for each age group separately, all groups are categorized according to the age group to which they cater. Groups for heterogeneous age groups are split and account for onethird for toddlers and two-thirds for older children, which reflects the regular shares of toddlers and older children in this type of group. The spatial accessibility measure for older children equals 0.044 and is about 2.5 times as high compared to younger children (with $A_{c y}=0.018$ on average), matching the higher utilisation rates for older children.

The results on the respective regressions, reported in Table 4, show that the findings for children below and above three years are very similar to each other, and also similar to the results for all children between zero and five, reported in the main part of the article: Spatial accessibility is higher in better neighbourhoods, and the non-profits significantly contribute to this inequality. These results hold for both age groups and irrespective of the applied measure of neighbourhood status. Public providers again tend to balance this inequality to some extent, but do so in a statistically significant way only when socio-economic status is measured by education. Note that the coefficients on neighbourhood status when investigating three- to five-year-old children are (in absolute terms) about twice as high compared to the younger age group, reflecting the differences in the mean and the variation of the endogenous variable on spatial accessibility. While we again find large differences between public and non-profit providers regarding the neighbourhoods primarily served by childcare services, we cannot find differences between these two provider types with respect to the two age groups of children. 
TABLE 4. Coefficient values derived from regressing accessibility of childcare by age category

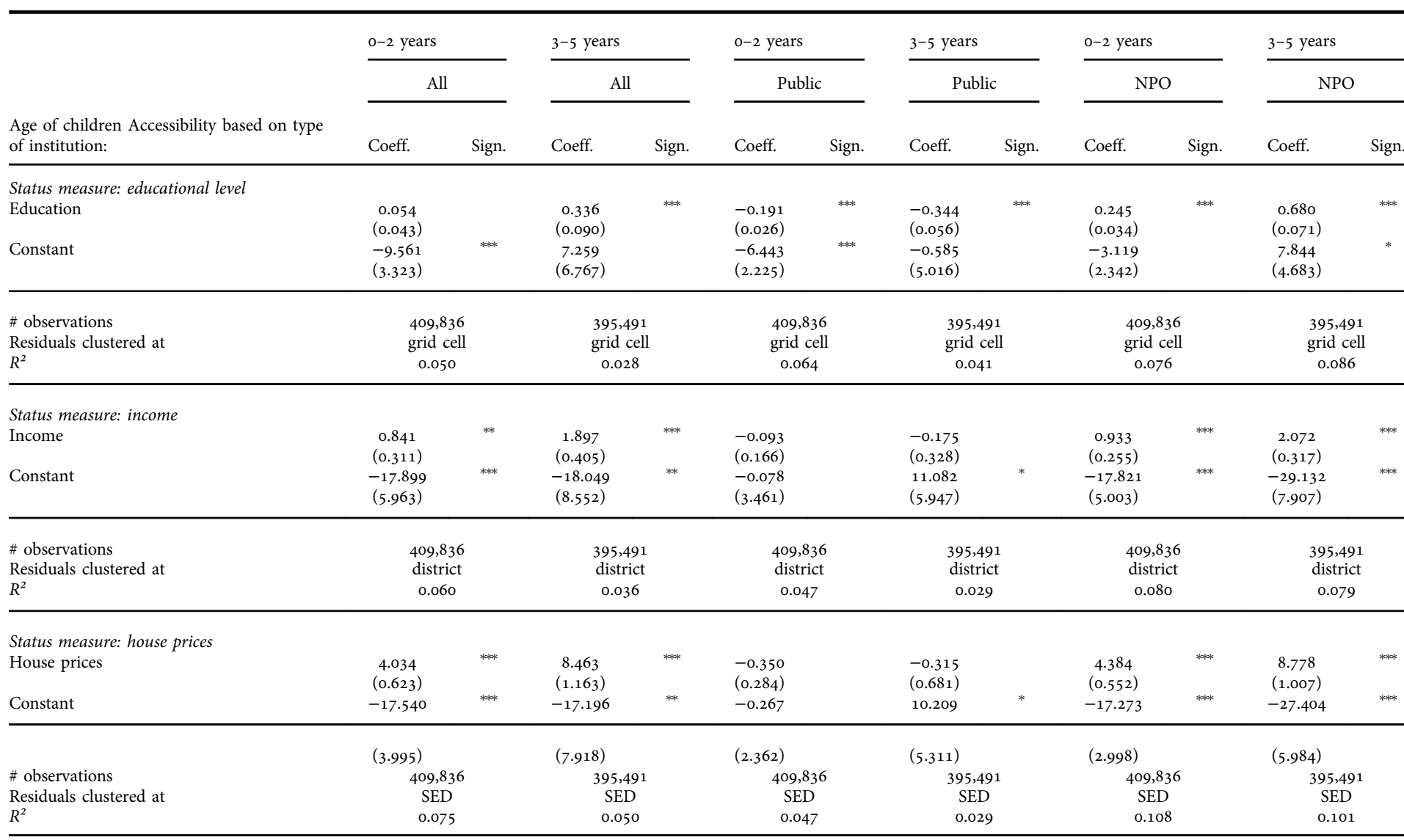

Notes: Accessibility measures are scaled by 1,000. All regressions include fixed year effects and additional variables on neighbourhood characteristics (on female employment rates, share of residents born in Austria or in other EU countries, and on connectivity). Standard errors are reported in parentheses and are based on standard errors that are clustered at the regional level at which the status measure is available. ${ }^{* * *}$ significant at $1 \%$, ${ }^{* *}$ significant at $5 \%$, ${ }^{*}$ significant at $10 \%$ level. 